\title{
Imported laryngeal and cutaneous diphtheria in tourists returning from western Africa to Sweden, March 2012
}

E Lindhusen-Lindhé (eva.lindhusen@vgregion.se) ${ }^{1}$, L Dotevall ${ }^{1}$, M Berglund $^{2}$

1. Department for Communicable Disease and Control, Västra Götaland Region, Sweden

2. Departement for ENT Diseases, Trollhättan, Västra Götaland Region, Sweden

Citation style for this article:

Lindhusen-Lindhé E, Dotevall L, Berglund M. Imported laryngeal and cutaneous diphtheria in tourists returning from western Africa to Sweden, March 2012. Euro Surveill. 2012;17(23):pii=20189. Available online: http://www.eurosurveillance.org/ViewArticle.aspx?Articleld=20189

Article submitted on 25 May 2012 / published on 7 June 2012

In March 2012 a 68-year-old woman was diagnosed with laryngeal diphtheria in a hospital in Västra Götaland Region, Sweden. Six days before symptom onset she had returned from a trip to western Africa where she had travelled accompanied by her husband. During the investigation, the 76 -year-old husband was diagnosed with cutaneous diphtheria. Both patients were incompletely vaccinated against diphtheria.

\section{Case report}

On 27 March 2012, a 68-year-old woman presented to the Ear, Nose and Throat (ENT) department in a hospital in Västra Götaland Region, western Sweden, with a five-day history of fever, coughing, hoarseness and increasing pain in the throat. She had a medical history of adult-onset diabetes mellitus and was under investigation for thrombocytopenia and suspected liver cirrhosis.

Six days prior to the onset of fever and throat symptoms she had returned from a two-week holiday in western Africa where she had travelled together with her husband and a friend.

Upon hospital admission, she presented with fever $\left(38.1^{\circ} \mathrm{C}\right)$, swelling of her soft palate and severe pain in the throat. A laryngoscopy was performed on the same day and revealed greyish membranes on and surrounding the vocal cords and the base of the tongue, and swollen larynx. These changes could not be seen by ordinary throat examination. Upon admission, the blood count was only mildly affected with slight decrease of the platelet count of $119 \times 10^{9} / \mathrm{L}$, (norm: $\left.165-387 \times 10^{9} / \mathrm{L}\right)$ and a total white blood cell count of $6.0 \times 10^{9} / \mathrm{L}$, (norm: 3.5-8.8 $\times 10^{9} / \mathrm{L}$ ) neutrophils $75 \%$. C-reactive protein was $46 \mathrm{mg} / \mathrm{L}$ (norm: $<5 \mathrm{mg} / \mathrm{L}$ ) and serum creatinine, $76 \mu \mathrm{mol} / \mathrm{L}$ (norm: $45-90 \mu \mathrm{mol} / \mathrm{L}$ ).

She had been referred to the ENT ward from the primary care clinic with an initial suspicion of a viral or fungal infection. On initial examination, the ENT physician suspected diphtheria although she had never encountered a case. Throat, nasal swabs and blood samples were sent for culture and sensitivity and the possibility of diphtheria was mentioned to the microbiology laboratory. However, the main suspected condition was fungal infection, and initially anti-fungal treatment was started.

The condition of the patient remained stable but due to the fever and throat pain symptoms antibiotic treatment with intravenous benzylpenicillin for a 14-day period was initiated three days after admission when the diphtheria was reconsidered as diagnosis because of primary treatment failure.

The Figure shows the laryngoscopy of the case four days after antibiotic treatment.

On the seventh day after hospital admission, the microbiology laboratory alerted the clinicians that a penicillin-sensitive strain of Corynebacterium diphtheriae grew from the throat culture. The Department of Communicable Disease Control and Prevention was notified immediately. The strain was sent to the Reference Laboratory (which

\section{FIGURE}

Laryngoscopy of index diphtheria case, four days after antibiotic treatment, Sweden, March 2012

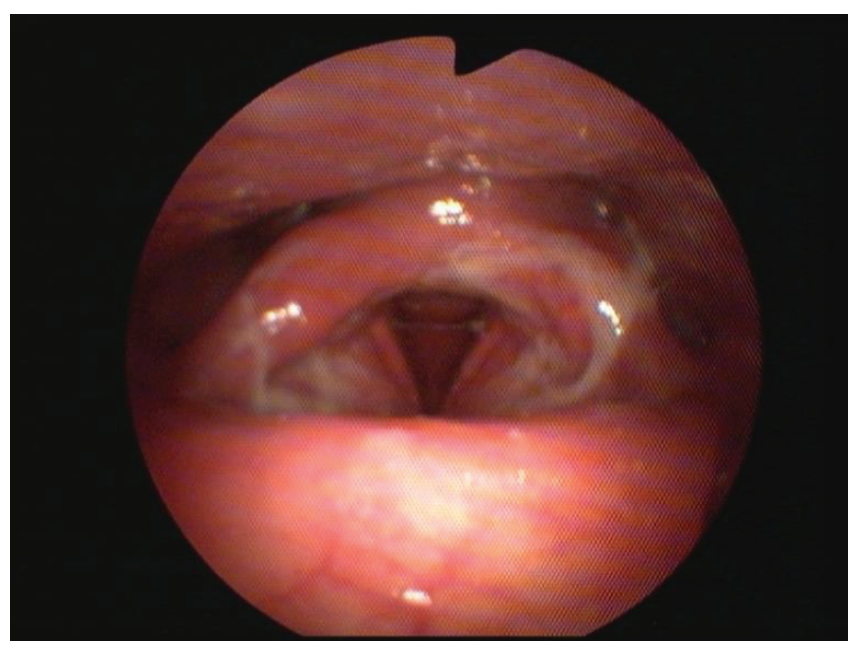


reports only gravis or non gravis strains) at the Swedish Institute for Communicable Disease Control (SMI, Solna) and eventually typed as a biovar non gravis strain with toxin production. Antitoxin treatment was not given since the patient was not systemically ill and there were no signs of renal or neurological complications. Her general condition improved after commencement of antibiotic treatment.

\section{Contact tracing}

Upon receipt of the culture result, tracing of close contacts of the index case was initiated immediately. In total, we examined 12 persons, none of them had any diphtheria symptoms and all were fully vaccinated against diphtheria.

\section{Travel companions}

The 76-year-old husband experienced several insect bites with secondary infection on his legs during the journey to western Africa. Several small secondary infected ulcers with purulent secretion and impetigolike appearance on his lower extremities were identified upon examination. He wasn't febrile or markedly ill during this period. Medical history revealed that he had probably received one earlier dose of vaccine against diphtheria during his military service in mid-1950s and a booster dose (combined tetanus-diphtheria vaccine) due to a minor injury more than 20 years ago. Cultures from throat and nose were collected, he was vaccinated against diphtheria, and he started prophylactic antibiotic treatment with erythromycin. He remained well and had no fever or mucosal symptoms. However, cultures from his wounds and pharynx were positive for toxin producing $C$. diphtheriae. Streptococcus pyogenes (Lancefield group A streptococcus) was also found. His clinical picture was interpreted as a mild cutaneous diphtheria without toxic symptoms. On the follow-up visit, his wounds appeared to have healed, and he showed no other signs of complication. Our speculation is that he may have been the source of infection for our index case, who had no skin lesions $[1,2]$.

The other travel companion was found to be completely unvaccinated against diphtheria. The culture results from their throat and nasal swabs were negative. They had received penicillin for a few days after arriving home for an unspecific soft tissue infection before culture was performed. They presented no other infective symptoms or complications.

\section{Other family members}

Children and grandchildren of the index case and of the husband were all vaccinated against diphtheria. A pregnant woman who had been in contact with the index case received a booster diphtheria vaccine dose since she was unsure whether she had received a booster previously. No other family members met the index case while she was contagious. No secondary cases were found.
Healthcare workers

The staff of the ENT department was also interviewed. Only a few of them could have been exposed to the saliva or sputum from the patient and were given an additional dose of diphtheria vaccine. The examining doctors who supposedly had the largest risk of getting the infection during throat examination were fully vaccinated against diphtheria. In accordance with the current recommendations [3], prophylaxis was not given to the healthcare workers.

\section{Discussion}

Diphtheria is a very rare disease in most European countries today. In 2009, 15 confirmed diphtheria cases were reported in five European countries, 47 were reported in 2008 and 21 in 2007 [4]. Occasional cases may therefore be undiagnosed and easily missed $[1,2,5,6]$. Correct treatment is therefore often delayed, as in the above cases. Unpublished data confirm previous findings that indicate that a large proportion of the Swedish citizens born before the general introduction of diphtheria vaccination have inadequate immunity against diphtheria and tetanus [7]. These age groups are often active travellers to endemic regions for diphtheria. In the absence of effective vaccine registration, both patients and doctors hesitate as to whether or not give primary vaccination when the patient seeks vaccination advice before travel. Our index patient is an experienced global traveller and has visited several travel medicine clinics during the recent years. Both the physicians in the travel medicine clinic and the patient presumed that she was properly vaccinated against diphtheria and no further investigations were made. There was no documentation of her earlier immunisation status. She was therefore given a booster dose. People travelling outside Europe and North America should always upgrade their diphtheria vaccination if not given within the last 20 years according to recommendations from the National Health Board in Sweden [7]. Tetanus vaccination is of course required even within Europe. Although vaccination does not guarantee immunity from contracting diphtheria, the protective effect against severe disease has been proved $[1,2]$.

Cutaneous diphtheria is less well recognised than respiratory infection. Signs and symptoms of the soft tissue infection due to $C$. diphtheriae may be mild and unspecific and may occur even in fully vaccinated patients $[1,2]$. Microbiological laboratories often do not look for $C$. diphtheriae routinely in throat swab or wound specimen. Furthermore, a co-infection due to Staphylococcus aureus or S. pyogenes is sometimes reported and may mask or delay the diagnosis of cutaneous diphtheria. Cutaneous diphtheria may cause secondary respiratory and cutaneous infections and may even be a source of outbreaks [1]. 


\section{Conclusion}

Although seldom encountered, diphtheria must be kept in mind when patients with respiratory symptoms, swollen palate and swollen neck ('bull neck') are admitted to hospital after returning from journeys in regions outside Europe and North America. It is also important to detect diphtheria in wound infections to avoid secondary transmission and to be aware of the possibility of toxic complications. Clinicians should be alerted to culture for diphtheria in patients with wound infections after journeys to endemic regions, and to alert the microbiologist that diphtheria may be a possible diagnostic. Vaccination advice to travellers to diphtheria-endemic areas should include upgraded vaccination against the disease. Single travel-related cases reinforce the importance of up-to-date immunisation especially in travellers to endemic countries. They also serve as reminders that clinicians need to be aware of the possibility of diphtheria, and to decrease the complacency that currently exists in many European countries concerning vaccine coverage in the adult population [8].

\section{References}

1. de Benoist AC, White JM, Efstratiou A, Kelly C, Mann G, Nazareth B, et al. Imported Cutaneous Diphtheria, United Kingdom. Emerg Infect Dis. 2004;10(3):511-3.

2. Orouji A, Kiewert A, Filser T, Goerdt S, Peitsch WK. Cutaneous diphteria in a German man with travel history. Acta Derm Venereol. 2012;92(2):179-80.

3. Heymann DL, editor. Control of communicable diseases manual. 19th ed. Washington, DC: American Public Health Association; 2008.

4. European Centre for Disease Prevention and Control (ECDC). Annual epidemiological report. Reporting on 2009 surveillance data and 2010 epidemic intelligence data. Stockholm: ECDC. 2011. Available from: http://www.ecdc.europa.eu/en/ publications/Publications/1111_SUR_Annual_Epidemiological_ Report_on_Communicable_Diseases_in_Europe.pdf

5. Wagner KS, White JM, Lucenko I, Mercer D, Crowcroft NS, Neal $\mathrm{S}$, et al. Diphtheria in the postepidemic period, Europe 20002009. Emerg Infect Dis. 2012;18 (2):217-25.

6. Fredlund H, Norén T, Lepp T, Morfeldt E, Henriques Normark B. A case of diphtheria in Sweden, October 2011. Euro Surveill. 2011;16(50): pii=20038. Available from: http://www. eurosurveillance.org/ViewArticle.aspx?Articleld $=20038$

7. Olin $\mathrm{P}, \mathrm{Carlssson} \mathrm{RM}$, Johansen $\mathrm{K}$, Hallander $\mathrm{H}$, Ljungman $\mathrm{M}$, Svensson A. Vaccinationsuppföljning: Seroepidemiologisk tvärsnittsstudie 1997, Slutrapport. [Vaccination follow up: sero-epidemiological cross-sectional study 1997, Final Report]. Swedish. Available from: http://www.smittskyddsinstitutet.se/ upload/Publikationer/SMI-rapport-reviderad-2006.pdf

8. Lai S, Efstratiou A. Report on the Sixth International Meeting of the European Laboratory Working Group on Diphtheria, Brussels, Belgium. Euro Surveill. 2002;7(1):pii=350. Available from: http://www.eurosurveillance.org/ViewArticle. aspx?Articleld $=350$ 